\title{
Screening of Cocaine and Its Metabolites in Human Urine Samples by Direct Analysis in Real-Time Source Coupled to Time-of-Flight Mass Spectrometry After Online Preconcentration Utilizing Microextraction by Packed Sorbent
}

\author{
Eshwar Jagerdeo a and Mohamed Abdel-Rehim ${ }^{\mathrm{b}, \mathrm{c}}$ \\ ${ }^{a}$ Federal Bureau of Investigation Laboratory, Quantico, Virginia, USA \\ ${ }^{\mathrm{b}}$ Department of Chemistry, Karlstad University, Karlstad, Sweden

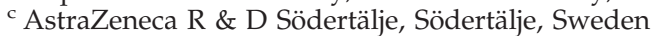

Microextraction by packed sorbent (MEPS) has been evaluated for fast screening of drugs of abuse with mass spectrometric detection. In this study, C8 (octyl-silica, useful for nonpolar to moderately polar compounds), $\mathrm{ENV}^{+}$(hydroxylated polystyrene-divinylbenzene copolymer, for extraction of aliphatic and aromatic polar compounds), Oasis MCX (sulfonic-poly(divinylbenzene-co-N-polyvinyl-pyrrolidone) copolymer), and Clean Screen DAU (mixed mode, ion exchanger for acidic and basic compounds) were used as sorbents for the MEPS. The focus was on fast extraction and preconcentration of the drugs with rapid analysis using a time-of-flight (TOF) mass spectrometer as the detector with direct analysis in a real-time (DART) source. The combination of an analysis time of less than 1 min and accurate mass of the first monoisotopic peak of the analyte and the relative abundances of the peaks in the isotopic clusters provided reliable information for identification. Furthermore, the study sought to demonstrate that it is possible to quantify the analyte of interest using a DART source when an internal standard is used. Of all the sorbents used in the study, Clean Screen DAU performed best for extraction of the analytes from urine. Using Clean Screen DAU to extract spiked samples containing the drugs, linearity was demonstrated for ecgonine methyl ester, benzoylecgonine, cocaine, and cocaethylene with average ranges of: 65-910, 75-1100, 95-1200, and 75-1100 ng/mL $(n=5)$, respectively. The limits of detection (LOD) for ecgonine methyl ester, benzoylecgonine, cocaine, and cocaethylene were $22.9 \mathrm{ng} / \mathrm{mL}, 23.7 \mathrm{ng} / \mathrm{mL}, 4.0 \mathrm{ng} / \mathrm{mL}$, and $9.8 \mathrm{ng} / \mathrm{mL}$ respectively, using a signal-to-noise ratio of 3:1. (J Am Soc Mass Spectrom 2009, 20, 891-899) (c) 2009 American Society for Mass Spectrometry

$\mathrm{B}$ iological samples such as plasma and urine are much more complex than many others due to the presence of proteins, salts, acids, bases, and various organic compounds with similar chemistry to the analytes of interest. As a result, the extraction methods for biological samples have been difficult. If an unsuitable sample preparation method has been employed before the injection, the entire analytical process can be wasted. The purpose of sample preparation is (1) removal of interfering substances to eliminate ion suppression, (2) conversion of the analytes into a more suitable form for injection, separation, and detection, and (3) preconcentration of the analytes to improve

Address reprint requests to Professor M. Abdel-Rehim, AstraZeneca R \& D Södertälje, Clinical Pharmacology and DMPK, SE-151 85 Södertälje, Sweden. E-mail: Mohamed.abdel-rehim@astrazeneca.com sensitivity. The procedure must be highly reproducible, with a high recovery of the target analytes. Microextraction by packed sorbent (MEPS) is a new miniaturized, solid-phase extraction method that can be connected online to a GC or LC system without any modifications. In MEPS approximately 1 to $2 \mathrm{mg}$ of the solid packing material is packed inside a syringe (100 to $250 \mu \mathrm{L}$ ) as a plug or between the barrel and the needle (Figure 1a). Sample preparation takes place on the packed bed, which can be coated to provide selective and suitable sampling conditions. This approach to sample preparation is very promising for many reasons: (1) it is easy to use, (2) it can be fully automated as an online procedure, (3) it is rapid, and (4) the cost of analysis is minimal compared with conventional solid-phase extraction. Hence, several drugs such as local anesthetics and their metabolites [1-3], the anticancer drugs rosco- 
(a)

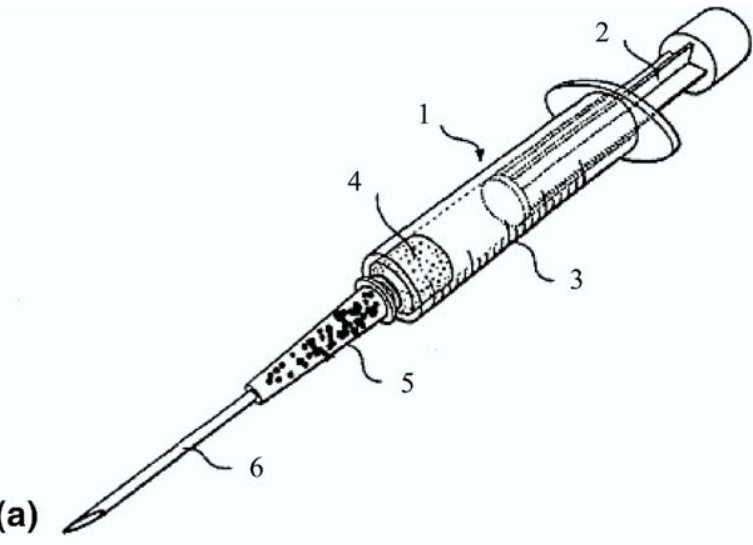

(b)

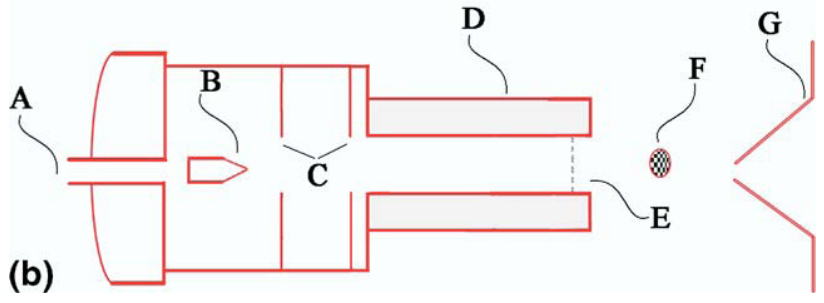

Figure 1. (a) A syringe (1) with a plunger (2) having a syringe barrel (3) slide ably within the barrel and a hollow needle (6) extending from the barrel through which needle the liquid sample is drawn into the syringe barrel characterized in that a solid-phase or coating material $(4,5)$ is provided in the syringe barrel $(4)$ or between the barrel and the needle (5). (b) Schematic of the direct analysis in real time (DART) source showing (a) Gas inlet in the source, (b) Needle electrode, (c) Perforated disk electrodes, (d) Gas heater, (e) Grid electrode, (f) Sample, (g) Mass spectrometer orifice.

vitine, olomoucine, busulfan, and cyclophosphamide [4-7], the $\beta$-blockers acebutolol and metoprolol [8], the neurotransmitters dopamine and serotonin [9], and methadone [10] have been extracted from biological samples such as blood, plasma, or urine samples using MEPS.

Direct analysis in real time (DART) was recently introduced as a new ion source and takes place in open air under ambient conditions. The DART source (Figure $1 b)$ operates by exposing the sample to a gas stream such as helium or nitrogen. Ionization is performed by reaction of electronic or vibrionic excited-state species [11-14] with reagent molecules and analytes. DART can be used for the analysis of gases, liquids, or solids, and is a useful tool for small molecules analysis, and not a technique for the analysis of large biomolecules such as proteins. The ionization mechanisms in the DART source are complex and do not follow a single process. Two of the known published mechanisms are penning ionization $[15,16]$ and proton transfer from water clusters $[17,18]$. Penning ionization is when a metastable atom transfers energy to an analyte $(\mathrm{M})$, resulting in the formation of a molecular ion $\mathrm{M}^{+}$. This process will occur if the analyte molecule $\mathrm{M}$ has an ionization energy less than the internal energy of the metastable ion. For the proton transfer from water clusters to occur in producing an $[\mathrm{M}+\mathrm{H}]^{+}$, the analyte (M) must have a higher proton affinity than the ionized water cluster.

Desorption electrospray ionization (DESI) is another open source ionization technique that was first introduced around the sample time as DART [19]. DESI forms ions from surfaces by exposure to electrosprayed solvent in a very high velocity gas stream. The DART is an atmospheric pressure glow discharge source, where the discharge is initiated by applying a potential between a needle electrode and a ground counter electrode [11, 12, 18]. The gas exits the glow discharge region of the DART source through the perforated disk electrode, gas heater, and a grid electrode (Figure 1b). Ionization occurs when the DART gas makes contact with the sample in the open gap between the DART source outlet and the orifice of the mass spectrometer. However, other glow discharge ionization techniques $[20,21]$ operate by introducing sample vapor through an orifice into a glow discharge region at reduced pressure. Unlike DART, possible sample loss could occur when introduced into a vacuum, and sample damage is possible on direct exposure to an electrical discharge.

Using DART alone for analysis of drugs of abuse at levels detected by other GC/MS and LC/MS techniques [22-33] is not achievable. Now, to improve the sensitivity of DART, sample pretreatment is required to preconcentrate the analytes because the current configuration does not have the highest transmission of ions into the mass spectrometer. As a result, the manufacturer of DART has a new device to be used between the DART source and the orifice of the mass spectrometer $[18,34]$. Preliminary data reported by the manufacturer demonstrate a significant improvement in ion transmission. This improvement should have a significant impact on this procedure as a screening or quantitation method.

Cocaine (C), an alkaloid from the plant species Erythroxylon coca, is one of the most widely abused drugs and is widely cultivated in South America. It is extensively metabolized to benzoylecgonine (BZE), ecgonine methyl ester (EME), and ecgonine (E) by plasma, liver esterases, and spontaneous chemical hydrolysis [35]. Evidence of enzymatic hydrolysis of $C$ to BZE has been demonstrated. C does slowly hydrolyze to BZE in an aqueous solution at $\mathrm{pH} 7.4$ or above [36]. BZE with a longer half-life than cocaine is of considerable importance in clinical and forensic toxicology applications. Cocaethylene (CE) is produced through transesterification following concurrent use of cocaine and ethanol [37]. It has been shown in pharmacokinetic studies of cocaine that $\sim 85 \%$ to $90 \%$ of a cocaine dose is recovered in the 24-h urine. The unchanged drug accounts for $1 \%$ to $9 \%$ of the dose depending on the urine $\mathrm{pH}$, while BZE and EME account for $35 \%$ to $54 \%$ and $32 \%$ to $49 \%$, respectively [38, 39]. However, forensic samples could be from a first time or a chronic user. The concentration of cocaine and metabolites can therefore extend over a wide range, depending on many condi- 
tions. GC/MS has long been the analytical choice for analysis of complex matrices due to its selectivity and sensitivity, and is often the reference method for analysis of drugs in biological matrices. However, in the past decade, the use of LC/MS has significantly increased for routine analysis because of its sensitivity and affordability. Although several GC/MS methods for cocaine and metabolites in urine and whole blood have previously been developed and are being used in the laboratory, these procedures are relatively timeconsuming, taking up to several hours [22-26]. Because of the demand for speed, sensitivity, and less timeconsuming methods, several LC, LC/MS, and LC/ MS/MS methods have been developed over the past decade [27-33]. Most of these methods require offline solid-phase extraction, which requires approximately 0.5 to $2 \mathrm{~mL}$ of urine, plasma, or blood. Because of the volume of sample required for the analysis, it is frequently difficult to perform a repeat extraction. Although LC/MS methods have helped to bring about a significant increase in speed and sensitivity, the instrument analysis time is still significant.

In this study, we describe a sample preparation method, MEPS, that requires a few microliters of sample and an extraction time of less than 2 min. Because of the small volume of sample needed for extraction, repeated analysis can be done. With the extraction performed within a few minutes, followed by analysis taking less than $1 \mathrm{~min}$, the result of a sample can be rapidly determined. This method uses a high-resolution time-of-flight mass spectrometer equipped with an atmospheric pressure ionization (API) interface that is used to identify compounds with the combination of accurate mass measurements and accurate isotopic abundances. In the future, coupling this extraction to a robotic autosampler and interfacing it with the DART/ TOF mass spectrometer will make this method fully automated.

\section{Experimental}

\section{Chemical and Reagent}

Certified standards, $100 \mu \mathrm{g} / \mathrm{mL}$ in methanol, of cocaine, $\mathrm{d}_{3}$-cocaine, cocaethylene, $\mathrm{d}_{3}$-cocaethylene, benzoylecgonine, ecgonine methyl ester, and $d_{3}$-ecgonine methyl ester were purchased from Cerilliant Corporation (Round Rock, TX). A d $\mathrm{d}_{5}$-benzoylecgonine standard was purchased from Cambridge Isotope Laboratories (Andover, MA).

Negative control urine was pooled from anonymous volunteers at the laboratory. Methanol, methylene chloride, and 2-propanol were purchased from Fisher Scientific (Pittsburgh, PA). Monobasic sodium phosphate and formic acid were purchased from Sigma Aldrich (St. Louis, MO). Dibasic sodium phosphate, ammonium hydroxide, and hydrochloric acid were purchased from
Fisher Scientific Corporation (Fair Lawn, NJ). Deionized water $\left(18+\mathrm{M} \Omega \mathrm{cm}^{-1}\right.$ grade) was obtained from an in-house Millipore purification system. Clean Screen DAU solid-phase extraction material was purchased from United Chemical Technologies Inc. (Bristol, PA). Oasis MCX was purchased from Waters Corporation (Milford, MA). The C8 and $\mathrm{ENV}^{+}$were purchased from Argonaut (Mid Glamorgan, United Kingdom).

\section{Instrumentation}

The mass spectrometer used was a JMS-100TLC (AccuTOF) atmospheric pressure ionization time-offlight mass spectrometer (JEOL USA, Peabody, MA), operated in the positive mode with a resolving power in excess of 6000 (FWHM definition). For all analyses, the orifice 1 voltage of the atmospheric interface was set to $30 \mathrm{~V}$ and the ring lens and orifice 2 voltage were set to 5 and $10 \mathrm{~V}$, respectively. A temperature of $80^{\circ} \mathrm{C}$ was applied to the orifices (Figure $1 \mathrm{~b}$ ). The RF ion guide potential was set to $600 \mathrm{~V}$. Data acquisition was set to acquire $\mathrm{m} / \mathrm{z}$ from 60 to 600 . The DART ion source was operated with helium gas at a flow rate of approx. 3.25 $\mathrm{L} /$ min during measurement. The source was purged with nitrogen when it was not being used. The gas heater was set to $400{ }^{\circ} \mathrm{C}$ for all analyses. The discharge needle electrode, perforated disk electrodes, and the grid electrode were set to $4000 \mathrm{~V}$, grounded, $250 \mathrm{~V}$, and $75 \mathrm{~V}$, respectively. The discharge needle electrode, perforated disk electrodes, grid electrode, and the gas heater temperature were optimized for the best response.

The mass scale calibration was accomplished by placing neat polyethylene glycol, with an average molecular weight of 600 , on a melting tube and passing it in front of the source for a few seconds. There was no memory effect or carryover of the reference compound after the polyethylene glycol had been removed. As a result, a full reference mass spectrum could be included in each data file, and accurate mass measurements could be accomplished for all samples. Before the introduction of the sample to the DART source, a few seconds of data were collected as the background. The time collected for the background was subtracted from the time for the sample to produce the spectrum of the sample.

\section{Preparation of Samples}

Stock solutions of C, BZE, EME, and CE were prepared in methanol with concentrations of 1200, 510, 450, and $520 \mu \mathrm{g} / \mathrm{mL}$, respectively. From the stock solutions, intermediate standard solutions were made in urine for C, BZE, EME, and CE with the concentrations 6.10, 5.10, 4.50, and $5.20 \mu \mathrm{g} / \mathrm{mL}$, respectively. An internal standard stock solution of $\mathrm{d}_{3}-\mathrm{C}, \mathrm{d}_{5}-\mathrm{BZE}, \mathrm{d}_{3}-\mathrm{EME}$, and $\mathrm{d}_{3}-\mathrm{CE}$ with concentrations of approximately $50 \mu \mathrm{g} / \mathrm{mL}$ was prepared in methanol. 
Using the intermediate standard solution in urine and the internal standard stock solution, an eight-point standard curve was prepared from urine samples with concentrations ranging from 45 to $2400 \mathrm{ng} / \mathrm{mL}$ in urine, depending on the analyte, with an internal standard concentration of $1000 \mathrm{ng} / \mathrm{mL}$. All the solutions were then diluted 1:1 with $0.1 \mathrm{M}$ phosphate buffer ( $\mathrm{pH}$ 6.0). Using these solutions, a standard curve ranging from 20 to $1200 \mathrm{ng} / \mathrm{mL}$, with an internal standard concentration of $500 \mathrm{ng} / \mathrm{mL}$, was prepared. Likewise, spiked samples were diluted with phosphate buffer.

\section{Sample Extraction and Preconcentration}

For this study, several solid-phase extraction (SPE) sorbents were evaluated for the extraction of cocaine and its metabolites from urine. The SPE sorbents used for this study were $\mathrm{C} 8, \mathrm{ENV}^{+}$, Oasis $\mathrm{MCX}$, and Clean Screen DAU. Since several different SPE materials were used in this study, two extraction procedures were used to maximize extraction efficiency and minimize carryover. The SPE materials were packed in individual $250 \mu \mathrm{L}$ syringes. Sample preparation included the fol-

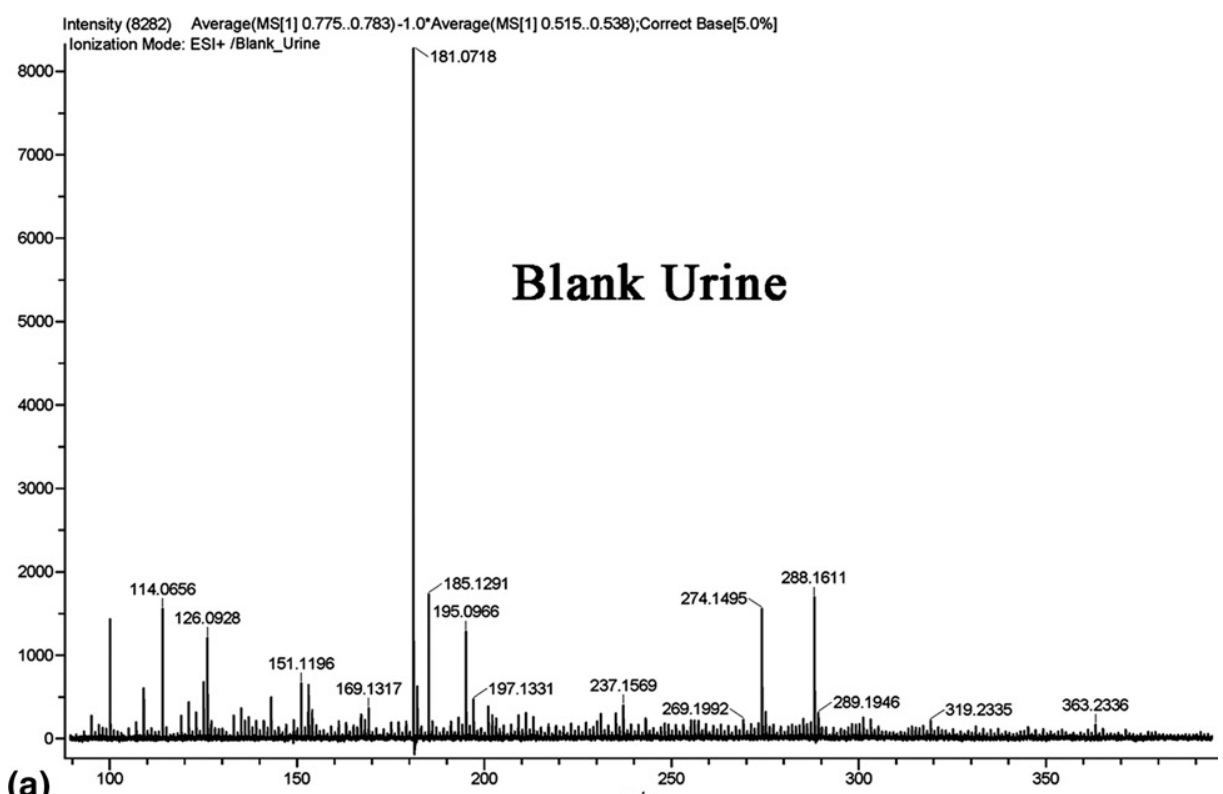

(a)

$\mathrm{m} / \mathrm{z}$

300 350

$\times 10^{3}$ Intensity (36568) Average(MS[1] 0.447..0.459)-1.0*Average(MS[1] 0.152..0.164);Correct Base[5.0\%]

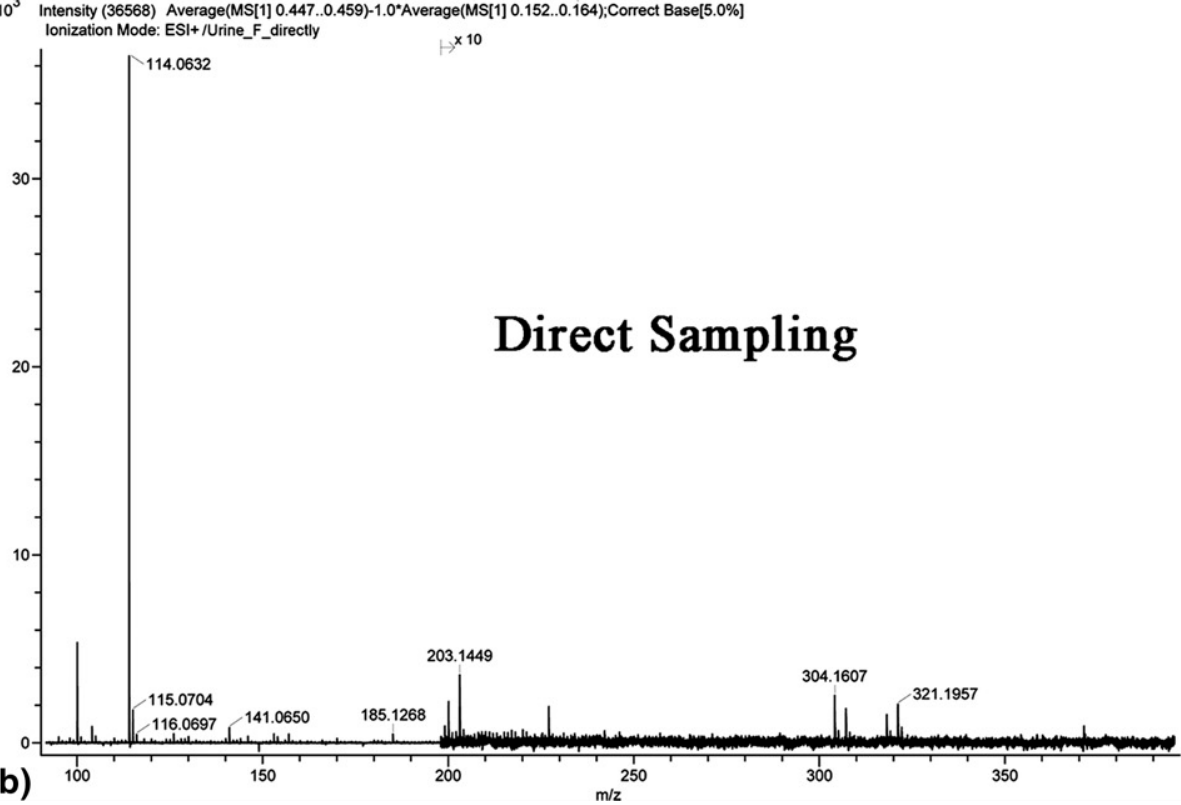

(b)

$\mathrm{m} / \mathrm{z}$

Figure 2. (a) Mass spectrum obtained with DART/TOF of a blank urine sample. Sample preparation: MEPS/Clean Screen DAU sorbent. (b) Mass spectrum obtained with DART/TOF of a urine sample spiked with cocaine, cocaethylene, benzoylecgonine, and ecgonine methyl ester at $611 \mathrm{ng} / \mathrm{mL}, 525$ $\mathrm{ng} / \mathrm{mL}, 458 \mathrm{ng} / \mathrm{mL}$, and $515 \mathrm{ng} / \mathrm{mL}$, respectively. 
lowing steps: conditioning, sample loading, washing, and, finally, analyte elution. Before the extraction procedure, the C8 syringe was conditioned with $250 \mu \mathrm{L}$ methanol, and twice with $250 \mu \mathrm{L}$ water. The urine sample was drawn over the SPE material and dispensed several times to improve the extraction. The syringe was then washed with $250 \mu \mathrm{L}$ water and the analytes were eluted with $100 \mu \mathrm{L}$ of a mixture of methylene chloride/2propanol/ammonium hydroxide (79.5:20:0.5). The syringe was cleaned three times with $250 \mu \mathrm{L}$ methanol containing $0.5 \%$ ammonium hydroxide, then twice with $250 \mu \mathrm{L} 100 \%$ water, twice with $250 \mu \mathrm{L}$ methanol containing $0.5 \%$ formic acid, and, finally, twice with $250 \mu \mathrm{L}$ water.

Before the extraction procedure, the syringes containing $\mathrm{ENV}^{+}$, Oasis MCX, and Clean Screen DAU were conditioned with $250 \mu \mathrm{L}$ of methylene chloride/2propanol/ammonium hydroxide (78:20:2) (eluting solvent), then twice with $250 \mu \mathrm{L}$ methanol, twice with 250 $\mu \mathrm{L}$ water, and, finally, with $250 \mu \mathrm{L}$ of $0.1 \mathrm{M}$ phosphate buffer. The urine sample was then drawn over the SPE sorbent, the same procedure as for the $\mathrm{C} 8$ sorbent. The syringe was then washed with $250 \mu \mathrm{L}$ water followed by $100 \mu \mathrm{L}$ eluting solvent. Finally, cleaning was done three times with $250 \mu \mathrm{L}$ methanol containing $2 \%$ ammonium hydroxide, twice with $250 \mu \mathrm{L}$ water, twice with $250 \mu \mathrm{L}$ methanol containing $2 \%$ formic acid, and, finally, twice with $250 \mu \mathrm{L}$ water.

\section{Sample Analysis}

Five $\mu \mathrm{L}$ of the extracted sample was added to the tip of a melting tube and placed immediately in front of the DART source. Within $1 \mathrm{~min}$ the analysis was completed and a new sample could be introduced using a new tip.

\section{Results and Discussion}

The procedure described here was carried out with the intention of achieving rapid screening of samples with minimal sample preparation. Analyzing the sample directly in the matrix produces unacceptable results, with a poor response for all the analytes (Figure $2 \mathrm{a}$ and b). This could be due to a combination of issues such as ion suppression and the distribution of the total mass present in the open source. Additionally, the depletion of the metastable atoms (critical for ionization) by other compounds in the complex matrix could limit the ionization of the analytes. The matrix and low concentration of drugs and their metabolites always present a challenge to screening methods. In this article, we describe MEPS as a good tool for drug screening. MEPS can be used for the extraction and preconcentration of metabolites and the parent drugs from urine and plasma. In developing a screening method, several SPE sorbents $\left(\mathrm{C} 8, \mathrm{ENV}^{+}\right.$, Oasis $\mathrm{MCX}$, and Clean Screen DAU) were evaluated. The purpose of the sample preparation is (1) removal of interfering substances to eliminate ion suppression, (2) conversion of the ana-
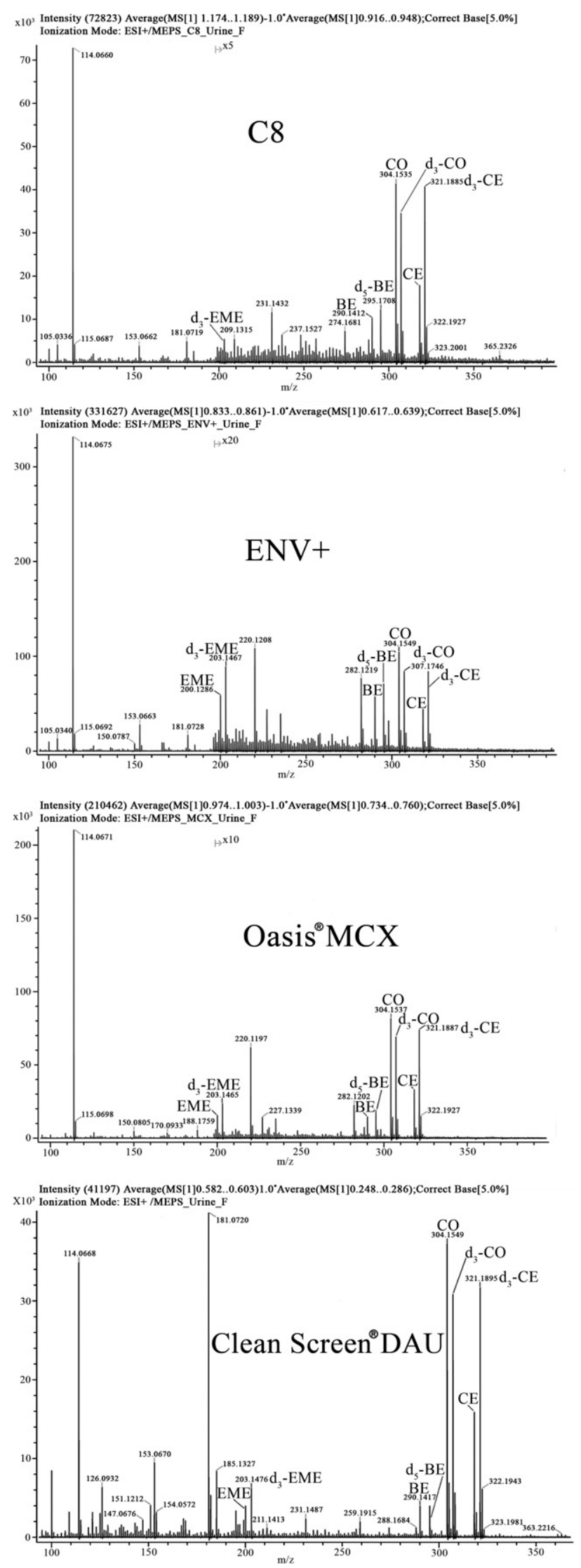

Figure 3. Mass spectrum obtained with DART/TOF of a urine sample spiked as in Figure 2, utilizing different sorbents (C8, ENV+, Oasis MCX, and Clean Screen DAU). 
Table 1. Regression parameters*

\begin{tabular}{lcccc}
\hline & Ecgonine methyl ester & Benzoylecgonine & Cocaine & Cocaethylene \\
\hline \hline $\mathrm{R}^{2}(n=6)$ & 0.992 & 0.995 & 0.991 & 0.991 \\
Slope & $0.00106 \pm 0.00051$ & $0.00298 \pm 0.00051$ & $0.00349 \pm 0.00168$ & $0.00246 \pm 0.00015$ \\
Intercept & $0.0141 \pm 0.0081$ & $0.0126 \pm 0.0423$ & $0.0071 \pm 0.0192$ & $0.01013 \pm 0.01062$ \\
\hline
\end{tabular}

${ }^{*}$ Average line equation $y=$ Average slope $( \pm 3 S D) x+$ Average intercept $( \pm 3 S D)$.

lytes into a more suitable form for injection, separation, and detection, and (3) preconcentration of the analytes to improve the sensitivity. The procedure must be highly reproducible, with a high recovery of the target analytes. The availability of cleaner and more reproducible sorbents, together with the large choice of sorbents over past years, has helped the increasing acceptance of and growing interest in SPE. There have been several reports of the application of SPE techniques to a wide variety of drugs and matrices.

\section{Preconcentration in MEPS Using Various Sorbents}

The most important parameters in SPE are the selection of the type and amount of the sorbent, the determination of the sample volume that can be applied without loss in recovery, the composition and volume of the washing solution that can be applied without loss of the analytes, and finally the composition and volume of the elution solution [40]. Silica-based sorbents such as C8 can contain a low concentration of ionized silanol groups capable of retaining basic solutes by an ionexchange mechanism. Thus, neutral and acidic compounds are absorbed onto the silica sorbent through hydrophobic interactions, whereas basic drugs are bound through both hydrophobic and ionic interactions. Copolymeric sorbents and mixed-mode sorbents such as Clean Screen DAU contain hydrophobic and ion-exchange functional groups. Mixed-mode sorbents have been developed for the isolation of most drugs of abuse and for classifying extracts into acid/neutral and basic drugs for systematic toxicological analysis.

The MEPS (C8) sorbent extracted cocaine, cocaethylene, a trace amount of benzoylecgonine, and no ecgonine methyl ester (Figure 3). Extraction using the $\mathrm{ENV}^{+}$ showed the presence of all the analytes, though at a much lower extraction efficiency than the C8 material. The signal to noise was also much better using this material than the C8 (Figure 3). The Oasis MCX produced results that demonstrate the presence of all the analytes at a much higher efficiency and improved signal to noise than the $\mathrm{ENV}^{+}$, though lower than the C8 (Figure 3). The SPE material that works best is the Clean Screen DAU material, which shows the presence of all the analytes with excellent signal to noise and mass accuracy compared with the other materials (Figure 3). Although the results were acceptable, the extraction efficiency of cocaine and cocaethylene were far more effective than benzoylecgonine and ecgonine methyl ester. This is due to the higher hydrophobicity of cocaine and cocaethylene, resulting in higher interaction and higher extraction efficiency for these compounds. The combination of MEPS for the extraction and detection with DART/TOF has proven successful. The extraction of the analytes from the matrix was achieved within a few minutes, followed by analysis that takes less than $1 \mathrm{~min}$. Moreover, having a TOF mass spectrometer as the detector has provided an accurate mass of the analyte and its isotopes for definitive confirmation. Having an instrument that requires little or no sample preparation, combined with accurate mass measurements, provides speed and specificity that is always aspired to in forensic investigations. In this experiment, in the positive ionization mode, $C$, BZE, EME, CE, $\mathrm{d}_{3}-\mathrm{C}, \mathrm{d}_{5}-\mathrm{BZE}, \mathrm{d}_{3}-\mathrm{EME}$, and $\mathrm{d}_{3}-\mathrm{CE}$ were protonated to produce ions of the form $[\mathrm{M}+\mathrm{H}]^{+}$with $m / z$ 304.1548, 290.1392, 200.1286, 318.1705, 307.1737, 295.1706, 203.1475, and 321.1893, respectively. The isotopes of C, BZE, EME, CE, $\mathrm{d}_{3}-\mathrm{C}, \mathrm{d}_{5}-\mathrm{BZE}, \mathrm{d}_{3}-\mathrm{EME}$, and $\mathrm{d}_{3}$-CE were monitored with $\mathrm{m} / \mathrm{z} 305.1581,291.1425$, 201.1318, 319.1738, 308.1769, 296.1738, 204.1507, and 322.1926 , respectively. The guidelines used for the presence of a compound are the accurate mass of the analyte and its isotopes, with mass errors less than $10 \mathrm{mmu}$, and its isotopic relative abundance. The number of possible elemental compositions generated for the average mass of the protonated molecule of cocaine and each of its metabolites was 1 when the following limits were applied: the elemental composition limits were $\mathrm{C}_{0-20}$, $\mathrm{H}_{0-42}, \mathrm{~N}_{0-1}, \mathrm{O}_{0-6}$ and the mass tolerance was set to 10 $\mathrm{mmu}$. For additional confirmation, ramping the cone voltage (30 to $100 \mathrm{~V})$ in the source of the mass spec-

Table 2. The accuracy at various concentrations in urine samples

\begin{tabular}{lccc}
\hline \multirow{1}{c}{ Analyte } & $\begin{array}{c}\text { Concentration } \\
(\mathrm{ng} / \mathrm{mL})\end{array}$ & $\begin{array}{c}\text { Mean } \\
\text { concentration } \\
(n=3)\end{array}$ & $\begin{array}{c}\text { Mean } \\
\text { accuracy \% } \\
(n=3)\end{array}$ \\
\hline \hline Ecgonine methyl & 229 & 260 & 113 \\
$\quad$ ester & 458 & 526 & 114 \\
Benzoylecgonine & 916 & 1065 & 116 \\
& 257 & 238 & 93 \\
Cocaine & 515 & 534 & 104 \\
& 1030 & 1059 & 103 \\
Cocaethylene & 305 & 333 & 109 \\
& 611 & 611 & 100 \\
& 1222 & 1215 & 100 \\
& 262 & 276 & 105 \\
& 525 & 526 & 100 \\
& 1049 & 1076 & 103 \\
\hline
\end{tabular}


Table 3. Accuracy at the lower limit of quantification (LLOQ)

\begin{tabular}{lccc}
\hline \multicolumn{1}{c}{ Analyte } & $\begin{array}{c}\text { Concentration } \\
\mathrm{ng} / \mathrm{mL}\end{array}$ & $\begin{array}{c}\text { Mean } \\
\text { concentration } \\
\mathrm{ng} / \mathrm{mL}(n=5)\end{array}$ & $\begin{array}{c}\text { Mean } \\
\text { accuracy \% } \\
(n=5)\end{array}$ \\
\hline \hline $\begin{array}{l}\text { Ecgonine methyl } \\
\quad \text { ester }\end{array}$ & 65 & 75.4 & 116 \\
$\begin{array}{l}\text { Benzoylecgonine } \\
\text { Cocaine }\end{array}$ & 75 & 65.8 & 87.7 \\
Cocaethylene & 95 & 89.4 & 94.1 \\
\hline
\end{tabular}

trometer generates an MS/MS-like spectrum. The MS/MS spectra give the accurate mass of the analyte and its fragments.

\section{Linear Range, Accuracy, and Selectivity}

In this study, an attempt was made to demonstrate that quantitation is possible using the combination of MEPS/DART/TOF if an internal standard is used. Standard curves were prepared in urine, extracted, and analyzed on the DART/TOF. For the construction of the calibration curve, 6 to 8 levels in human urine were used for the studied analytes. Linearity was demonstrated for ecgonine methyl ester, benzoylecgonine, cocaine, and cocaethylene in the average ranges 65 to $920 \mathrm{ng} / \mathrm{mL}, 75$ to $1100 \mathrm{ng} / \mathrm{mL}, 95$ to $1200 \mathrm{ng} / \mathrm{mL}$, and 75 to $1100 \mathrm{ng} / \mathrm{mL}(n=5)$, respectively. The concentration of the internal standard was $500 \mathrm{ng} / \mathrm{mL}$. The data presented in Table 1 reveal that a good linear relationship was obtained. The results show a close correlation between the concentrations and relative peak areas for the analytes studied.

The method was validated using quality-control samples at three concentration levels. The accuracy varied from $113 \%$ to $116 \%$ for ecgonine methyl ester, $93 \%$ to $104 \%$ for benzoylecgonine, $99.5 \%$ to $109 \%$ for cocaine, and $100 \%$ to $105 \%$ for cocaethylene. The results obtained are listed in Table 2.

A urine sample spiked with a mixture of analytes and the internal standard was analyzed and compared with an extracted urine blank. No significant interference was detected from the extracted urine blank sample. Representative mass spectra of blank urine and spiked urine sample are presented in Figure $3 a$ and b.

\section{Limit of Detection (LOD) and Lower Limit of Quantitation (LLOQ)}

The LODs for ecgonine methyl ester, benzoylecgonine, cocaine, and cocaethylene were 22.9, 23.7, 4.0, and 9.8 $\mathrm{ng} / \mathrm{mL}$, respectively using a signal-to-noise ratio of $3: 1$. The LLOQs for ecgonine methyl ester, benzoylecgonine, cocaine, and cocaethylene were 65, 75, 95, and 75 $\mathrm{ng} / \mathrm{mL}$, respectively, using a signal-to-noise ratio $>10.0$. The variation in accuracy of the LLOQ for cocaine and metabolites was in the range of $\pm 16 \%$ of the nominal concentration values (Table 3 ). The results showed close correlation coefficients $(>0.99)$ for all analytes in the calibration range studied.

Table 4. Comparison of LOD, LLOQ extraction and analysis time and accuracy between this study and earlier studies for cocaine and its metabolites

\begin{tabular}{|c|c|c|c|c|c|}
\hline & Cocaine & Cocaethylene & Benzoylecgonine & Ecgonine methyl ester & Reference/method \\
\hline \multirow[t]{5}{*}{ LOD (ng/mL) } & * & * & * & * & [30] (GC/MS) \\
\hline & 75 & * & 35 & 90 & [31] (LC/UV) \\
\hline & * & * & * & * & [22] (GC/MS) \\
\hline & 1 & 1 & 1 & * & [32] (LC/MS) \\
\hline & 4 & 10 & 24 & 23 & Present study \\
\hline \multirow[t]{5}{*}{ LOO (ng/mL) } & 500 & * & 500 & 500 & [30] (GC/MS) \\
\hline & 220 & $*$ & 100 & 260 & [31] c(LC/UV) \\
\hline & 10 & * & 10 & 10 & [22] (GC/MS) \\
\hline & 10 & 10 & 10 & * & [32] (LC/MS) \\
\hline & 95 & 75 & 75 & 65 & Present study \\
\hline \multirow[t]{5}{*}{ Extraction time $(\mathrm{h})$} & $>2$ & $*$ & $>2$ & $>2$ & [30] (GC/MS) \\
\hline & $>2$ & * & $>2$ & $>2$ & [31] (LC/UV) \\
\hline & $>2$ & * & $>2$ & $>2$ & [22] (GC/MS) \\
\hline & $>2$ & $>2$ & $>2$ & * & [32] (LC/MS) \\
\hline & $<0.02$ & $<0.02$ & $<0.02$ & $<0.02$ & Present study \\
\hline \multirow[t]{5}{*}{ Analysis time (min) } & 7 & $*$ & 7 & 7 & [30] (GC/MS) \\
\hline & 28 & * & 28 & 28 & [31] (LC/UV) \\
\hline & 11 & * & 11 & 11 & [22] (GC/MS) \\
\hline & 33 & 33 & 33 & * & [32] (LC/MS) \\
\hline & $<1$ & $<1$ & $<1$ & $<1$ & Present study \\
\hline \multirow[t]{5}{*}{ Accuracy of LOQ (\%) } & 100 & * & 96 & 96 & [30] (GC/MS) \\
\hline & 86 & * & 87 & 87 & [31] (LC/UV) \\
\hline & 104 & * & 104 & 107 & [22] (GC/MS) \\
\hline & 102 & 100 & 98 & * & [32] (LC/MS) \\
\hline & 94 & 102 & 88 & 107 & Present study \\
\hline
\end{tabular}

*No published data. 


\section{Method Comparison}

The results of the present study were compared with the results from the literature (Table 4). The results from this study are in close agreement with earlier published data. Furthermore, this method reduced the extraction time by hundred times and analysis time was reduced by tenfold compared with earlier studies. This work demonstrates that quantitation can be performed on an open source mass spectrometer with very short extraction and analysis times. The sensitivity of the present method is high in comparison to the published methods (Table 4). As a result, the manufacturer of the DART has a new device to be used between the DART source and the orifice of the mass spectrometer [18, 34]. This method was intended to be used as a quick screening method. However, the authors have gone to great lengths to demonstrate that an open source can be used for quantitation.

\section{Conclusions}

This study has demonstrated that the combination of MEPS with DART/TOF can be a very useful tool for screening drugs of abuse in a biological matrix. MEPS can be used for the extraction and preconcentration of metabolites and the parent drugs from the biological matrices. The combined speed of extraction and detection performed within a few minutes is too striking to be ignored. The accurate mass of the analyte and its isotopes provides greater confidence in identification. The study demonstrates that it is possible to quantitate an analyte if a suitable internal standard is used employing MEPS/DART/TOF. Furthermore, having the extraction material in a syringe lends itself to automation and, when interfaced with the DART/TOF, could provide a completely automated system.

\section{Acknowledgments}

Names of commercial products and manufacturers are provided for identification purposes only. Inclusion does not imply endorsement by the Federal Bureau of Investigation or the United States Federal government.

\section{References}

1. Abdel-Rehim, M. New Trend in Sample Preparation: On-Line Microextraction in Packed Syringe for Liquid and Gas Chromatography Applications: I. Determination of Local Anesthetics in Human Plasma Samples Using Gas Chromatography-Mass Spectrometry. J. Chromatogr. B. 2004, 801, 317-321.

2. Abdel-Rehim, M.; Altun, Z.; Blomberg, L. Microextraction in Packed Syringe (MEPS) for Liquid and Gas Chromatographic Applications. Part II. Determination of Ropivacaine and Its Metabolites in Human Plasma Samples Using MEPS with Liquid Chromatography/Tandem Mass Spectrometry. J. Mass Spectrom. 2004, 39, 1488-1493.

3. Altun, Z.; Blomberg, L. G.; Jagerdeo, E.; Abdel-Rehim, M. Drug Screening Using Microextraction in a Packed Syringe (MEPS)/Mass Spectrometry Utilizing Monolithic-, Polymer-, and Silica-Based Sorbents. J. Liquid Chromatogr. Relat. Technol. 2006, 29, 829-839.

4. Vita, M.; Skansen, P.; Hassan, M.; Abdel-Rehim, M. Development and Validation of a Liquid Chromatography and Tandem Mass Spectrometry Method for Determination of Roscovitine in Plasma and Urine Samples Utilizing On-Line Sample Preparation. J. Chromatogr. B. 2005, 817, 303-307.
5. Vita, M.; Abdel-Rehim, M.; Nilsson, C.; Hassan, Z.; Skansen, P.; Wan, H.; Meurling, L.; Hassan, M. Stability, pKa and plasma protein binding of roscovitine. J. Chromatogr. B. 2005, 821, 75-80.

6. Abdel-Rehim, M.; Skansen, P.; Vita, M.; Hassan, Z.; Blomberg, L.; Hassan, M. Microextraction in packed syringe/liquid chromatography/ electrospray tandem mass spectrometry (MEPS/LC/MS/MS) for quantification of olomoucine in human plasma samples. Anal. Chim. Acta. 2005, 539, 35-39.

7. Said, R.; Hassan, Z.; Hassan, M.; Abdel-Rehim, M. Rapid quantification of cyclophosphamide in patients plasma samples using microextraction in packed syringe (MEPS) on-line with liquid chromatography-tandem mass spectrometry. J. Liquid Chromatogr. Relat. Technol. 2008, 31, 683694.

8. El-Bealiqq, A.; Kussak, A.; Blomberg, L.; Abdel-Rehim, M. Microextraction in packed syringe/liquid chromatography/electrospray tandem mass spectrometry for quantification of acebutolol and metoprolol in human plasma and urine samples. J. Liquid Chromatogr. Relat. Technol. 2007, 30, 575-586.

9. El-Bealiqq, A.; Kussak, A.; Abdel-Rehim, M. Determination of dopamine and serotonin in human urine samples utilizing microextraction in packed syringe online with liquid chromatography/electrospray tandem mass spectrometry. J. Sep. Sci. 2007, 30, 421-424.

10. El-Bealiqq, A.; Abdel-Rehim, M. Quantitative analysis of methadone in human urine samples by microextraction in packed syringe-gas chromatography-mass spectrometry (MEPS-GC-MS). J. Sep. Sci. 2007 30, 2501-2505.

11. Cody, R. B.; Larameee, J. A. U.S. Patent Number 6, 949:741, 2005.

12. Laramee, J. A.; Cody, R. B. U.S. Patent Number 7,112,785, 2006.

13. Cody, R. B.; Laramee, J. A.; Durst, H. D. Versatile new ion source for the analysis of materials in open air under ambient conditions. Anal. Chem. 2005, 77, 2297-2302.

14. Jones, R. W.; Cody, R. B.; McClelland, J. F. Differentiating writing inks using direct analysis in real time mass spectrometry. J. Forensic Sci. 2006, 51, 915-918.

15. Penning, F. M. Uber Ionization durch metastable Atome. Naturwissenschaften 1927, 15, 818 .

16. Baldwin, K. G. H. Metastable helium: Atom optics with nano-grenades Contemp. Phys. 2005, 46, 105

17. Laramee, J. A.; Cody, R. B.; Niles, J. M.; Durst, H. D. Forensic application of DART Mass Spectrometry in Forensic Analysis on the Cutting Edge. John Wiley and Sons, Inc.: Hoboken, NJ, 2007, p. 175-195.

18. Laramee, J. A.; Cody, R. B. Chemi-Ionization and Direct Analysis in Real Time Mass Spectrometry. In The Encyclopedia of Mass Spectrometry: Molecular Ionization Methods, Vol, VI. Gross, M.L.; Caprioli, R.M.; Eds.; Amsterdam, 2007, p. 377-387.

19. Takats, Z.; Wiseman, J.; Gologan, B.; Cooks, R. G. Mass spectrometry sampling under ambient conditions with desorption electrospray ionization. Science 2004, 306, 471-473.

20. Guzowski, J. P.; Brockaert, J. A. C.; Ray, S. J.; Hieftje, G. M. Development of a direct current gas sampling glow discharge ionization source for the time-of-flight mass spectrometer. J. Anal. Atmos. Spectrom. 1999, 14 1121-1127.

21. McLuckey, S. A.; Glish, G. L.; Asano, K. G.; Grant, B. C. Atmospheric sampling glow discharge ionization source for the determination of trace organic compounds in ambient air. Anal. Chem. 1988, 60, 22202227.

22. Crouch, D. J.; Alburges, M. E.; Spanbauer, A. C.; Rollins, D. E.; Moody, D. E.; Chasin, A. A. Analysis of cocaine and its metabolites from biological specimens using solid-phase extraction and positive ion chemical ionization mass spectrometry. J. Anal. Toxicol. 1995, 19, 352-358.

23. Spanbaurer, A. C.; Moody, D. E.; Foltz, R. L.; Walsh, S. L. A gas chromatographic-positive ion chemical ionization-mass spectrometric method for determination of cocaine, benzoylecgonine, ecgonine methyl ester, and norcocaine in plasma: Detection of norcocaine in plasma after oral administration of cocaine. J. Anal. Toxicol. 2000, 24, 453-455.

24. Abusada, G. M.; Abukhalaf, I. K.; Alford, D. D.; Vinzon-Bautista, I Prasmanik, A. K.; Ansari, N. A.; Manno, J. E., Manno, B. R. Solid-phase extraction and GC/MS quantitation of cocaine, ecgonine methyl ester, benzoylecgonine, and cocaethylene from meconium, whole blood, and plasma. J. Anal. Toxicol. 1993, 17, 353-358.

25. Cone, E. J.; Hillsgrove, M.; Darwin, W. D. Simultaneous measurement of cocaine, cocaethylene, their metabolites, and "crack" pyrolysis products by gas chromatography-mass spectrometry. Clin. Chem. 1994, 40, 1299-1305.

26. Lin, S.; Moody, D. E.; Bigelow, G. E.; Foltz, R. L. A Validated Liquid Chromatography-Atmospheric Pressure Chemical Ionization-Tandem Mass Spectrometry Method for Quantitation of cocaine and benzoylecgonine in Human Plasma. J. Anal. Toxicol. 2001, 25, 497-503.

27. Klingmann, A.; Skopp, G.; Aderjan, R. Analysis of cocaine, benzoylecgonine, ecgonine methyl ester, and ecgonine by high pressure liquid chromatography-API mass spectrometry and application to short-term degradation study of cocaine in plasma. J. Anal. Toxicol. 2001, 25, 425-430.

28. Jamdar, S. C.; Pantuck, C. B.; Diaz, J.; Mets, B. A rapid, sensitive assay for cocaine and its metabolites in biological fluids using solid-phase extraction and high-performance liquid chromatography. J. Anal. Toxicol. 2000, 24, 438-441.

29. Diamond, F. X.; Vickery, W. E.; Kanel, J. Extraction of benzoylecgonine (cocaine metabolite) and opiates (codeine and morphine) from urine samples using the Zymark RapidTrace. J. Anal. Toxicol. 1996, 20, 587-591. 
30. Isenschmid, D. S.; Levine, B. S.; Caplan, Y. H. A comprehensive study of the stability of cocaine and its metabolites. J. Anal. Toxicol. 1988, 12, 242-245.

31. Virag, L.; Mets, B.; Jamdar, S. Determination of cocaine, norcocaine, benzoylecgonine, and ecgonine methyl ester in rat plasma by highperformance liquid chromatography with ultraviolet detection. J. Chromatogr. B 1996, 681, 263-269.

32. Clauwaert, K.; Decaestecker, T: Mortier, K.; Lambert, W.; Deforce, D. Peteghem, C. V.; Bocxlaer, J. V. The Determination of Cocaine, Benzoylecgonine, and Cocaethylene in Small-Volume Oral Fluid Samples by Liquid Chromatography-Quadrupole-Time-of-Flight Mass Spectrometry. J. Anal. Toxicol. 2004, 28, 655-659.

33. Srinivasan, K.; Wang, P.; Eley, A. T.; White, C. A.; Bartlett, M. G. Liquid chromatography-tandem mass spectrometry analysis of cocaine and its metabolites from blood, amniotic fluid, placental and fetal tissues: Study of the metabolism and distribution of cocaine in pregnant rats. J. Chromatogr. B 2000, 745, 287-303.
34. Laramee, J. A.; Durst, H. D.; Connell, T. R.; Nilles, J. M. Detection of chemical warfare agents on surfaces relevant to Homeland Security by Direct Analysis in Real-Time Spectrometry. Am. Lab. 2008, 40, 16-20.

35. Jatlow, P. L. Drug of abuse: Cocaine. Clin. Chem. 1987, 33, 66B-71B.

36. Stewart, D. J.; Inaba, T.; Lucassen, M.; Kalow, W. Cocaine Metabolism: Cocaine and norcocaine hydrolysis by liver and serum esterases. Clin. Pharmacol. Ther. 1979, 25, 464-468.

37. Jatlow, P. L. Cocaethylene: pharmacologic activity and clinical significance. Ther. Drug. Monit. 1993, 15, 533-536.

38. Ambre, J.; Ruo, T. L.; Nelson, J.; Belknap, S. Ecgonine methyl ester, A major metabolite of cocaine. J. Anal. Toxicol. 1988, 12, 301-306.

39. Baselt, R. C.; Chang, R. Urinary excretion of cocaine and benzoylecgonine following oral ingestion in a single subject. J. Anal. Toxicol. 1987, 11, 81-82.

40. Poole, C. V. New Trends in solid phase extraction. Trends Anal. Chem. 2003, 22, 362-373. 